\title{
Effects of Mind-Body Training on Cytokines and Their Interactions with Catecholamines
}

\author{
Joon Hwan Jang', Hye Yoon Park², UI Soon Lee ${ }^{3}$, Kyung-Jun Lee ${ }^{2}$, and Do-Hyung Kang ${ }^{2,4} \bowtie$ \\ ${ }^{1}$ Department of Medicine, Seoul National University College of Medicine, Seoul, Republic of Korea \\ ${ }^{2}$ Department of Neuropsychiatry, Seoul National University Hospital, Seoul, Republic of Korea \\ ${ }^{3}$ Global Cyber University, Cheonan, Republic of Korea \\ ${ }^{4}$ Department of Psychiatry, Seoul National University College of Medicine, Seoul, Republic of Korea
}

Objective Mind-body training (MBT) may control reactions to stress and regulate the nervous and immune systems. The present study was designed to assess the effects of MBT on plasma cytokines and their interactions with catecholamines.

Methods The study group consisted of 80 subjects who practice MBT and a control group of 62 healthy subjects. Plasma catecholamine (norepinephrine, NE; epinephrine, E; and dopamine, DA) and cytokine (TNF-alpha, IL-6, IFN-gamma, and IL-10) levels were measured, and the differences between the MBT and control groups and the interactions of cytokines with catecholamines were investigated.

Results A significant increase in IL-10+IFN-gamma was found in females of the MBT group compared with controls. Also, a significant increase of IL-10 (anti-inflammatory cytokine) in the MBT group was shown in a specific condition in which TNF-alpha and IL-6 (pro-inflammatory cytokines) are almost absent $(\leq 1 \mathrm{ng} / \mathrm{L})$ compared with controls. In the MBT group, significant positive correlations were found between IL-10 and the NE/E ratio and between IL-10 and the DA/E ratio, whereas the control group did not show any such correlations.

Conclusion MBT may increase IL-10, under specific conditions such as a decrease of pro-inflammatory cytokines or E, which may regulate the stress response and possibly contribute to effective and beneficial interactions between the nervous and immune systems.

Psychiatry Investig 2017;14(4):483-490

Key Words Mind-body training, Stress, Cytokines, Catecholamines.

\section{INTRODUCTION}

The mind is based not solely on brain structure and function but on the continuous interactions of the brain with the body and external world. ${ }^{1}$ The positive attitude of a person who controls stress through mind-body training $(\mathrm{MBT})^{2}$ is expected to improve the regulation of the nervous and immune systems, because stress affects both systems. ${ }^{3}$ Thus, stress reduction through $\mathrm{MBT}$, as shown in our previous study, ${ }^{2}$ contributes to the health of both the nervous and immune systems, which closely interact with one another. ${ }^{4}$

Received: March 7, 2016 Revised: May 18, 2016

Accepted: August 24, 2016 Available online: May 17, 2017

$\triangle$ Correspondence: Do-Hyung Kang, MD, PhD

Department of Neuropsychiatry, Seoul National University Hospital, 101 Daehak-ro, Jongno-gu, Seoul 03080, Republic of Korea

Tel: +82-2-2072-0690, Fax: +82-2-747-9063, E-mail: basuare@daum.net

(a) This is an Open Access article distributed under the terms of the Creative Commons Attribution Non-Commercial License (http://creativecommons.org/licenses/bync/4.0) which permits unrestricted non-commercial use, distribution, and reproduction in any medium, provided the original work is properly cited.
Pro-inflammatory cytokines such as tumor necrosis factor (TNF)-alpha and interleukin (IL)-6 promote inflammation, whereas anti-inflammatory cytokines such as IL-10 suppress the activity of pro-inflammatory cytokines. ${ }^{5,6}$ However, IFNgamma, which possesses antiviral activity and is associated with auto-inflammatory activity and autoimmune diseases, may function differentially depending on the biological process. ${ }^{5}$ IFN-gamma is a pro-inflammatory cytokine because it augments TNF activity and induces nitric oxide, ${ }^{5}$ whereas IFNgamma and macrophages play key roles in anti-inflammatory activity. ${ }^{7}$ Higher levels of burnout symptoms result in higher TNF-alpha levels, ${ }^{8}$ and IL-6 is significantly higher in melancholic subjects. ${ }^{9}$ Mental stress increases IL-6 (pro-inflammatory cytokines) ${ }^{10}$ whereas MBT decreases IL- $6 .{ }^{11}$

The interaction of the central and autonomic nervous systems is altered by MBT meditation. ${ }^{12}$ Furthermore, the brain and immune systems are involved in functionally relevant cross-talk in which the central nervous system receives messages from the immune system, and messages from the brain 
modulate immune functions, whose main function is to maintain homeostasis. ${ }^{4}$ In our previous studies, we found stress reduction in the MBT group compared with the control group. ${ }^{2}$ Using the same samples as those in the previous study, we planned to elucidate the effects of MBT on cytokines related to the immune system and hypothesized that the decreased stress through MBT induces beneficial effects on the immune system. Also, we found the increased DA levels in MBT group in our previous study. On the basis of this previous result, we tried to find the association of cytokines with catecholamines as one of the effects of MBT in this study. ${ }^{2}$ Other previous studies have reported the effects of meditation on catecholamines ${ }^{13}$ or cytokines, ${ }^{11}$ and the results have been controversial, but to date, there are no reports regarding the interactions between catecholamines and cytokines with regard to the effects of MBT. Thus, the goal of this study was to elucidate the effects of MBT on cytokines and their interactions with catecholamines induced by MBT.

\section{METHODS}

\section{Subjects}

This study was approved by the Institutional Review Board at Seoul National University Hospital, and written informed consent was obtained from all participants after the procedures had been explained fully. This study was conducted in accordance with the Declaration of Helsinki. The Structured Clinical Interview for DSM-IV Non-patient Version was used for assessing psychiatric disorders in participants. Exclusion criteria included a lifetime history of psychosis, bipolar disorder, major depressive disorder, substance abuse or dependence, a significant head injury, a seizure disorder, or mental retardation. Subjects who were already practicing MBT were recruited in the MBT group, and subjects who were not practicing it participated in the control group voluntarily. This is not a randomized controlled or longitudinal study but a crosssectional study. No significant differences were observed in age or gender between the MBT $(n=80)$ and control $(n=62)$ groups. The MBT group consisted of 80 subjects (men $=40$, women $=40$ ) who regularly practiced $\mathrm{MBT}$, ranging in age from 18 to 36 years (mean \pm SD, 26 \pm 3 ). The control group consisted of 62 healthy subjects $(\operatorname{men}=38$, women $=24$ ) who did not have prior experience with mind-body techniques with ages ranging from 19 to 37 years (25 \pm 4$)$. This study focused on a number of subjects who were homogeneous in age and practiced the same MBT. Plasma catecholamine and cytokine levels were measured in the same samples. Each blood sample was extracted at a random time during the day in both the control and MBT groups. The timing of the blood sample extraction was irrelevant to when the subjects engaged in MBT.

\section{The content and methods of the MBT}

Subjects who were engaged in MBT usually participated in a one-hour program for about four or five days per week. The subjects in the MBT group had practiced MBT for a mean of 44 months (range, 3-144 months). A total of 29 out of 80 subjects had more than 5 years of MBT experience. All subjects in the MBT group engaged in Brain Wave Vibration MBT, which is a technique designed to relax both mind and body through natural rhythmic movements. This MBT consists of a series of Body and Brain Holistic Fitness exercises, including three types of content: physical movements, deep breathing exercises, and meditation practices. The first content consists of physical movements, which are designed to ameliorate the physical symptoms resulting from the secretion of stress hormones and to improve the condition of the body. ${ }^{14}$ The second content consists of deep breathing exercises designed to facilitate the health of the limbic system that can become disrupted under the influence of stress and to improve emotional regulation and self-regulation. ${ }^{15}$ The third content consists of meditation practices designed to enhance mental mindfulness, peace of mind, concentration, and the ability to handle stress. ${ }^{16,17}$ Although the actual practice of this discipline resembles yoga, martial arts, and meditation, this process also has distinctive content described as brain respiration, which focuses primarily on the brain and its development, including the Brain Wave Vibration. A comparative study by Bowden et al. provides more details about the way in which MBT is both different from and similar to mindfulness meditation and yoga. ${ }^{18}$

\section{Cytokine assays}

Blood was collected in anticoagulant EDTA tubes. After centrifugation, the separated plasma was frozen at $-80^{\circ} \mathrm{C}$. TNFalpha, IL-6 (both from R\&D Systems, Minneapolis, MN, USA), IFN-gamma, and IL-10 (both from Pierce Endogen, Rockford, IL, USA) were measured using enzyme-linked immunosorbent assay kits. Absorbance was measured at $450 \mathrm{~nm}$ in a microplate reader (Versamax; Molecular Devices, Sunnyvale, CA, USA). All plasma samples were coded such that the investigators ran the assay in a blinded condition. All measurements were run in triplicate, and the average values were used in the statistical analyses after subtracting the average value of the blanks.

\section{Catecholamine measurements and analysis}

\section{Catecholamine measurements}

Blood was collected in anticoagulant EDTA tubes. The plasma separated by centrifugation was frozen at $-80^{\circ} \mathrm{C}$. The levels of catecholamines were measured using the same blood samples as those from the cytokine assay. The plasma levels of 
catecholamines were determined by high performance liquid chromatography. The mobile phase was a mixture supplied by Chromsystem (München, Germany). A mixture of norepinephrine (NE), dopamine (DA), and epinephrine (E) was used as an external standard at predetermined concentrations and supplied by the same company. Dihydroxybenzylamine was used as the internal standard. A plasma catecholamine analysis system marketed by Chromsystem was used. A CLC-300 dosing pump with a flow rate of $1.1 \mathrm{~mL} / \mathrm{min}$ was connected to a reverse-phase catecholamine C-80 (code no. 5100/K) column. A model CLC-100 electrochemical detector was used, with its signal registered and integrated by the Chromsystem Geminyx registry and calculation terminal.

\section{Absolute levels and relative ratio analysis of plasma catecholamines}

Plasma catecholamine levels were analyzed by two different methods. The first method involved measuring the absolute quantities of NE, E, and DA, and the second involved analysis of the relative levels of these substances, yielding data such as the NE/E and DA/E ratios. Catecholamines are derived from the amino acid tyrosine. Catecholamine-secret- ing cells use several reactions to convert tyrosine serially to L-DOPA and then to DA, which may be converted further to NE or even further to E. ${ }^{19}$ Thus, the relative ratio of catecholamines can represent the relative quantity depending on the individual capacity of catecholamines. Stressful stimulus significantly increased the NE and E levels and a slight decrease in the NE/E ratio was observed following mental stress. ${ }^{20}$ The decrease of the NE/E ratio in spite of the increase of the NE and $\mathrm{E}$ levels ${ }^{20}$ indicates the relatively greater increase of $\mathrm{E}$ than that of NE. Also, phenylethanolamine N-methyltransferase (PNMT) is an enzyme that converts NE to $\mathrm{E}$, and an increase in stress hormones can cause PNMT to convert more NE into E. Thus, it is thought that this relative analysis is meaningful and beneficial for elucidating the specific action and role of each catecholamine.

\section{Statistical analysis}

Pearson's correlation coefficient was used to investigate the relationship between two variables, and the Bonferroni correction was used to counteract the problem of multiple comparisons. The data were analyzed using Student's t-test to determine if two sets of data are significantly different from

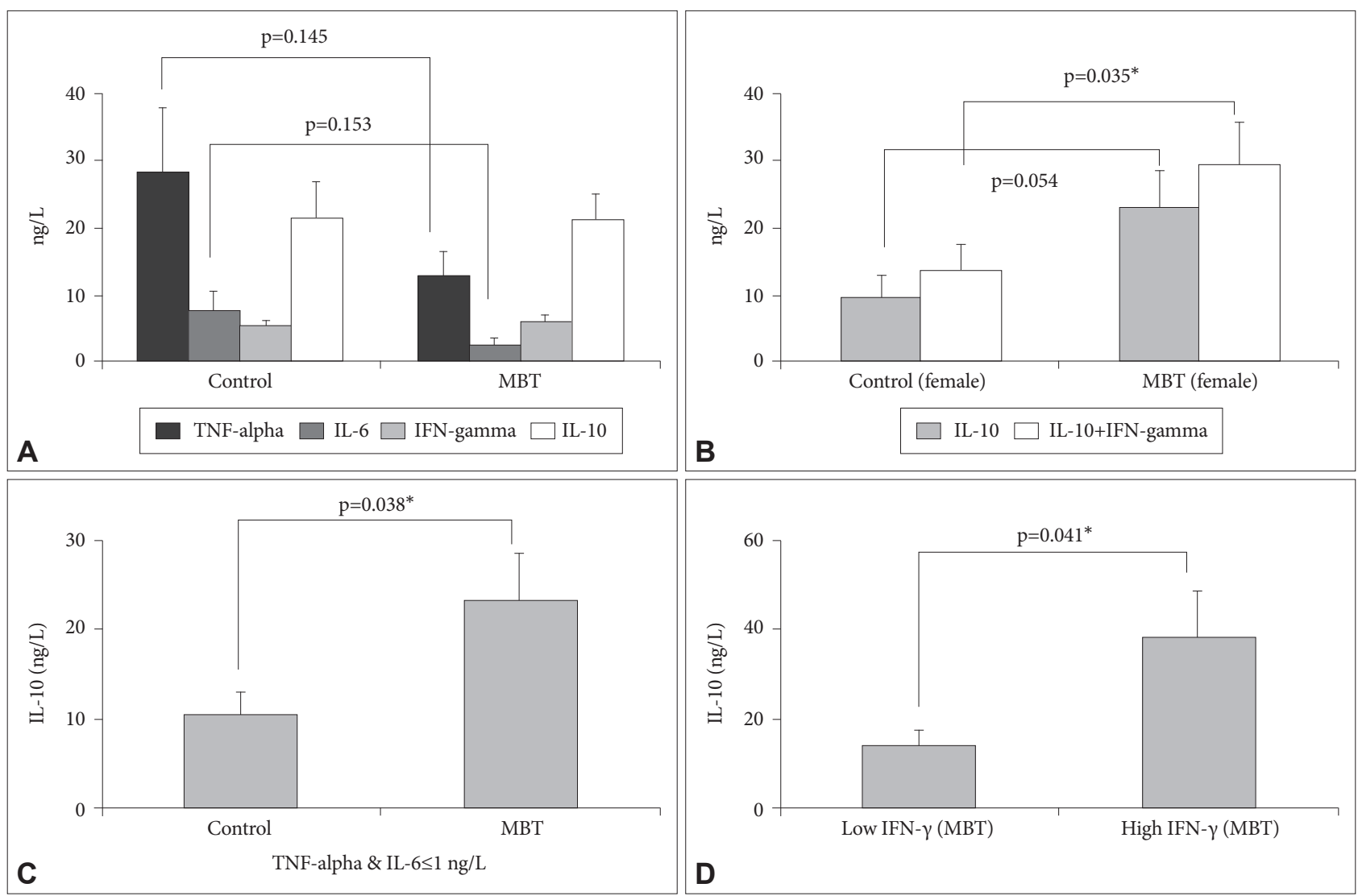

Figure 1. Plasma cytokine levels (TNF-alpha, IL-6, IFN-gamma, IL-10) in the control and MBT groups. A: Control $(N=62)$, $M B T(N=80)$. $B$ : Female groups: control $(\mathrm{N}=24)$, MBT $(\mathrm{N}=40)$. C: The increase of IL-10 in the MBT group when TNF-alpha and IL-6 were below $1 \mathrm{ng} / \mathrm{L}$. Control $(\mathrm{N}=36)$, MBT $(\mathrm{N}=48)$. D: The increase of IL-10 in the high IFN-gamma subgroup $(\mathrm{N}=23)$ compared with the low IFN-gamma $(\mathrm{N}=57)$ in the MBT group. Low or high IFN-gamma levels are based on the median split. ${ }^{*} p<0.05$. MBT: mind-body training. 
each other, and p-values less than 0.05 were considered statistically significant.

\section{RESULTS}

TNF-alpha and IL-6 levels in the MBT group showed lower levels than the control group, but did not reach the significant p-value (Figure 1A). A significant increase in IL-10+IFNgamma was found in the females of the MBT group compared with the females in the control group ( $\mathrm{p}=0.035)$ (Figure $1 \mathrm{~B}$ ), but no difference was observed in males. The increase of IL10 was shown in the females of the MBT group, but did not reach the significant $\mathrm{p}$-value $(\mathrm{p}=0.054)$ (Figure $1 \mathrm{~B})$. In cases with low levels of pro-inflammatory cytokines (TNF-alpha and IL- $6 \leq 1 \mathrm{ng} / \mathrm{L}$ ), IL-10, which suppresses the activity of proinflammatory cytokines, was increased significantly in the MBT group compared with the control group ( $\mathrm{p}=0.038$ ) (Figure $1 \mathrm{C}$ ). The criteria of less than $1 \mathrm{ng} / \mathrm{L}$ TNF-alpha and IL-6 levels indicate that these pro-inflammatory cytokines were practically absent. And, the criteria are meaningful and supported based on the report that TNF- $\alpha$ blockade induces IL10 expression. ${ }^{21}$ As the criteria are regarded as a useful method to elucidate dynamic interactions between pro-inflammatory cytokines and anti-inflammatory cytokines or between cytokines and catecholamine levels, we analyzed our results on the basis of the criteria and the significant statistical results, which supported the importance of the criteria. Also, IL-10 was higher in the high IFN-gamma subjects than in the low IFN-gamma subjects in the MBT group ( $\mathrm{p}=0.041$ ) (Figure 1D), implying that IFN-gamma may play the synergic and beneficial roles for the increase of IL-10 in the MBT group.

In the low E level subgroup on the basis of the median split, IL-10 level subtracted by TNF-alpha or IL-6 in the MBT group was increased compared with the control group (Figure 2), indicating that the increase of anti-inflammatory cytokine (IL-10) showed counteracting effect against pro-inflammatory cytokines (TNF-alpha and IL-6). As E occurs in response to stress, ${ }^{22}$ the higher IL-10 level in low $\mathrm{E}$ is a meaningful result showing the beneficial effects of MBT on cytokines.

To find the possible interactions of cytokines with catecholamines, we investigated the correlations between cytokines and catecholamine ratios. The Bonferroni correction was applied only in correlation analyses, and p-values less than 0.006 were considered statistically significant. In the MBT group, the positive correlation was found between IL-10 and the DA/ $\mathrm{E}$ ratio ( $\mathrm{p}=0.002)$, and the correlation between IL-10 and the $\mathrm{NE} / \mathrm{E}$ ratio $(\mathrm{p}=0.007)$ fell short of significant $\mathrm{p}$-value $(\mathrm{p}<0.006)$, whereas the control group did not show any such correlations (Table 1).

We investigated the factors responsible for the results displayed in Table 1 . We analyzed the additional correlations between cytokines and catecholamine ratios on the basis of the median split for stress and IL-10 and the corresponding criteria ( $1 \mathrm{ng} / \mathrm{L}$ ) for TNF-alpha and IL-6. First, subjects were divided into low and high stress groups based on the median split. When we analyzed the correlations between cytokines and catecholamine ratios in the low and high stress subgroups of the control group, we could not determine any correlation. However, in the MBT group, positive correlations were found between IL-10 and both the NE/E $(p=0.005)$ and DA/E ratios $(p=0.006)$ in the low stress subgroup, whereas the high stress subgroup did not show any such (Table 2). Second, we divided the data according to the corresponding criteria (1 ng/L) for TNF-alpha and IL-6 levels. In the control group, there was no correlation between cytokines and catecholamine ratios according to the TNF-alpha and IL-6 level $1 \mathrm{ng} / \mathrm{L}$ criterion. However, in the MBT group, a positive correlation was shown between IL-10 and the NE/E ratio $(\mathrm{p}=0.002)$ in the subgroup

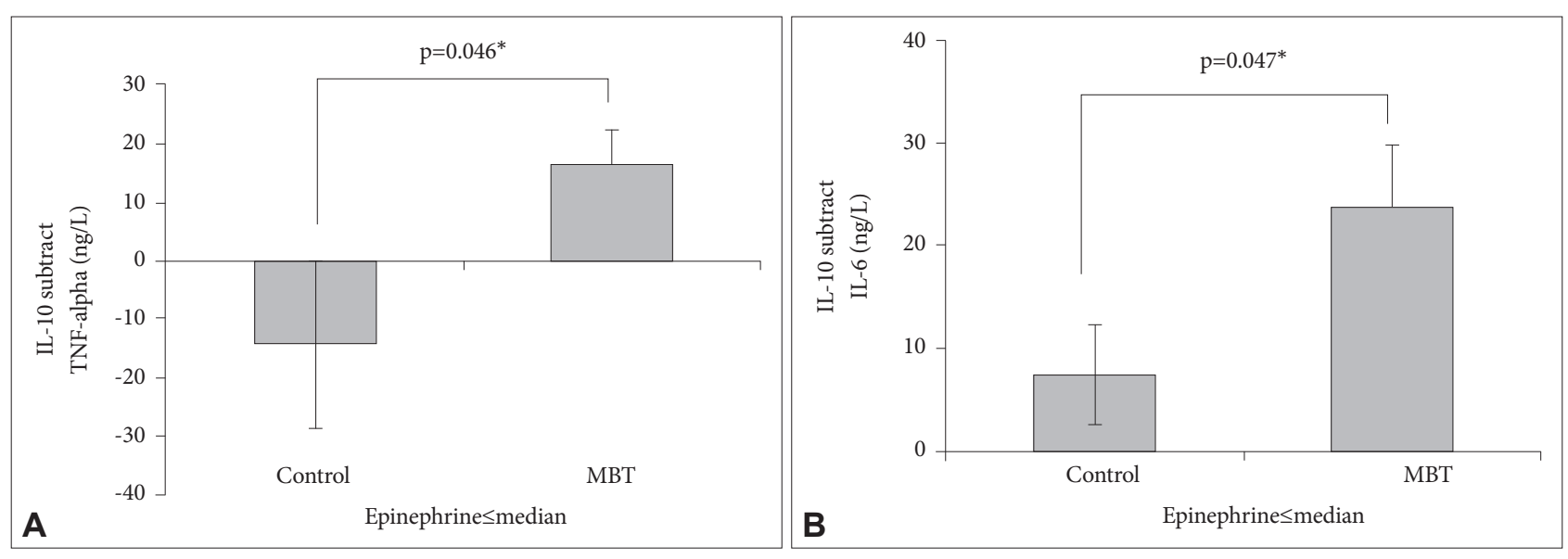

Figure 2. The increase of IL-10 against TNF-alpha and IL-6 in low E subgroups of the MBT group compared with the control group. A: IL-10 subtract TNF-alpha levels in low $E$ subgroups of both groups (E $\leq$ median levels). B: IL-10 subtract IL-6 levels in low $E$ subgroups of both groups ( $E \leq$ median levels). A and $B$ : Control group: $N=36$, MBT group: $N=44 .{ }^{*} p<0.05$. MBT: mind-body training. 
with less than $1 \mathrm{ng} / \mathrm{L}$ of both TNF-alpha and IL-6 (Table 3). Also, in the subgroup with less than $1 \mathrm{ng} / \mathrm{L}$ IL-6 levels in the MBT group, positive correlations were found between IL-10 and the NE/E ratio $(\mathrm{p}=0.003)$ and between IL-10 and the DA/ $\mathrm{E}$ ratio ( $\mathrm{p}=0.001$ ) (Table 3 ). On the other hand, the subgroups with greater than $1 \mathrm{ng} / \mathrm{L}$ TNF-alpha and IL-6 levels in the MBT group did not show any correlation between cytokines and catecholamine ratios (Table 3). Third, the high IL-10 level subgroup of the MBT group showed positive correlations between $\mathrm{IL}-10$ and the NE/E ratio $(\mathrm{r}=0.740, \mathrm{p}<0.001)$ and between IL-
10 and the DA/E ratio $(\mathrm{r}=0.561, \mathrm{p}=0.007)$, whereas the low IL-10 level subgroup did not show any correlations (Table 4). However, we were unable to determine any correlation between cytokines and catecholamine ratios in the low or high IL-10 subgroups of the control group.

\section{DISCUSSION}

A significant increase in IL-10+IFN-gamma was found in females of the MBT group compared with controls. More-

Table 1. Correlations between cytokines and catecholamine ratios

\begin{tabular}{|c|c|c|c|c|c|c|c|c|}
\hline \multirow{2}{*}{$\begin{array}{l}\text { Catecholamine } \\
\text { ratios }\end{array}$} & \multicolumn{4}{|c|}{$\begin{array}{c}\text { Control group }(\mathrm{N}=62) \\
\text { Cytokines }(\mathrm{ng} / \mathrm{L})\end{array}$} & \multicolumn{4}{|c|}{$\begin{array}{l}\text { MBT group }(\mathrm{N}=80) \\
\text { Cytokines }(\mathrm{ng} / \mathrm{L})\end{array}$} \\
\hline & TNF- $\alpha$ & IL-6 & IFN- $\gamma$ & IL-10 & TNF- $\alpha$ & IL-6 & IFN- $\gamma$ & IL-10 \\
\hline $\mathrm{NE} / \mathrm{E}(\mathrm{r})$ & -0.077 & -0.050 & -0.148 & -0.104 & -0.057 & -0.001 & -0.081 & 0.300 \\
\hline (p-value) & 0.552 & 0.700 & 0.251 & 0.423 & 0.617 & 0.991 & 0.472 & 0.007 \\
\hline $\mathrm{DA} / \mathrm{E}(\mathrm{r})$ & -0.069 & -0.077 & -0.092 & -0.069 & -0.063 & -0.009 & -0.092 & $0.336^{*}$ \\
\hline (p-value) & 0.593 & 0.552 & 0.478 & 0.595 & 0.579 & 0.940 & 0.419 & $0.002^{*}$ \\
\hline
\end{tabular}

r: correlation coefficient. ${ }^{*} \mathrm{p}<0.006$. MBT: mind-body training

Table 2. Correlations between cytokines and catecholamine ratios according to stress levels in the MBT group

\begin{tabular}{|c|c|c|c|c|c|c|c|c|}
\hline \multirow{2}{*}{$\begin{array}{l}\text { Catecholamine } \\
\text { ratios }\end{array}$} & \multicolumn{4}{|c|}{$\begin{array}{c}\text { Low stress group }(\mathrm{N}=57) \\
\text { Cytokines }(\mathrm{ng} / \mathrm{L})\end{array}$} & \multicolumn{4}{|c|}{$\begin{array}{l}\text { High stress group }(\mathrm{N}=16) \\
\text { Cytokines }(\mathrm{ng} / \mathrm{L})\end{array}$} \\
\hline & TNF- $\alpha$ & IL-6 & IFN- $\gamma$ & IL-10 & TNF- $\alpha$ & IL-6 & IFN- $\gamma$ & IL-10 \\
\hline $\mathrm{NE} / \mathrm{E}(\mathrm{r})$ & -0.049 & -0.044 & -0.067 & $0.364^{*}$ & -0.193 & 0.312 & -0.262 & -0.186 \\
\hline (p-value) & 0.716 & 0.747 & 0.623 & $0.005^{*}$ & 0.473 & 0.239 & 0.327 & 0.491 \\
\hline $\mathrm{DA} / \mathrm{E}(\mathrm{r})$ & -0.024 & -0.002 & -0.114 & $0.361^{*}$ & -0.371 & -0.043 & -0.072 & 0.055 \\
\hline (p-value) & 0.862 & 0.989 & 0.400 & $0.006^{*}$ & 0.157 & 0.873 & 0.792 & 0.840 \\
\hline
\end{tabular}

r: correlation coefficient. ${ }^{*} \mathrm{p}<0.006$. MBT: mind-body training

Table 3. Correlations between cytokines and catecholamine ratios according to TNF-alpha and IL-6 levels in the MBT group

\begin{tabular}{|c|c|c|c|c|c|c|}
\hline \multirow[t]{2}{*}{$\begin{array}{c}\text { Catecholamine } \\
\text { ratios }\end{array}$} & & $\begin{array}{r}\mathrm{TNH} \\
>1 \mathrm{ng} / \\
\text { Cyto }\end{array}$ & $\begin{array}{l}\text { IL-6 } \\
(\mathrm{N}=8) \\
\mathrm{g} / \mathrm{L})\end{array}$ & & $\begin{array}{c}\text { TNF- } \alpha \text { and IL-6 } \\
\leq 1 \text { ng/L group }(\mathrm{N}=48) \\
\text { Cytokines }(\mathrm{ng} / \mathrm{L})\end{array}$ & $\begin{array}{c}\text { IL-6 } \\
\leq 1 \text { ng/L group }(\mathrm{N}=67) \\
\text { Cytokines }(\mathrm{ng} / \mathrm{L})\end{array}$ \\
\hline & TNF- $\alpha$ & IL-6 & IFN- $\gamma$ & IL-10 & IL-10 & IL-10 \\
\hline NE/E (r) & 0.325 & 0.306 & 0.125 & 0.164 & $0.433^{*}$ & $0.360^{*}$ \\
\hline (p-value) & 0.432 & 0.460 & 0.767 & 0.697 & $0.002 *$ & $0.003^{*}$ \\
\hline $\mathrm{DA} / \mathrm{E}(\mathrm{r})$ & -0.476 & -0.125 & -0.195 & -0.323 & 0.239 & $0.404^{*}$ \\
\hline (p-value) & 0.233 & 0.768 & 0.644 & 0.435 & 0.101 & $0.001^{*}$ \\
\hline
\end{tabular}

r: correlation coefficient. ${ }^{*} \mathrm{p}<0.006$. MBT: mind-body training

Table 4. Correlations between cytokines and catecholamine ratios according to IL-10 levels in the MBT group

\begin{tabular}{|c|c|c|c|c|c|c|c|c|}
\hline \multirow{2}{*}{$\begin{array}{c}\text { Catecholamine } \\
\text { ratios }\end{array}$} & \multicolumn{4}{|c|}{$\begin{array}{l}\text { Low IL-10 group }(\mathrm{N}=58) \\
\text { Cytokines }(\mathrm{ng} / \mathrm{L})\end{array}$} & \multicolumn{4}{|c|}{$\begin{array}{l}\text { High IL-10 group }(\mathrm{N}=22) \\
\text { Cytokines }(\mathrm{ng} / \mathrm{L})\end{array}$} \\
\hline & TNF- $\alpha$ & IL-6 & IFN- $\gamma$ & IL-10 & TNF- $\alpha$ & IL-6 & IFN- $\gamma$ & IL-10 \\
\hline$\overline{\mathrm{NE} / \mathrm{E}(\mathrm{r})}$ & -0.121 & 0.121 & -0.059 & -0.096 & -0.021 & -0.071 & -0.175 & $0.740^{*}$ \\
\hline (p-value) & 0.367 & 0.367 & 0,658 & 0.475 & 0.928 & 0.753 & 0.437 & $0.000^{*}$ \\
\hline $\mathrm{DA} / \mathrm{E}(\mathrm{r})$ & -0.130 & 0.226 & -0.063 & -0.166 & -0.056 & -0.132 & -0.244 & 0.561 \\
\hline (p-value) & 0.330 & 0.087 & 0.641 & 0.212 & 0.806 & 0.557 & 0.273 & 0.007 \\
\hline
\end{tabular}

r: correlation coefficient. ${ }^{*} \mathrm{p}<0.006$. MBT: mind-body training 
over, a significant increase of IL-10 (anti-inflammatory cytokine) in the MBT group was shown in a specific condition in which TNF-alpha and IL-6 (pro-inflammatory cytokines) are almost absent $(\leq 1 \mathrm{ng} / \mathrm{L})$ compared with controls. In the MBT group, significant positive correlations were found between IL-10 and the NE/E ratio and between IL-10 and the $\mathrm{DA} / \mathrm{E}$ ratio, whereas the control group did not show any such correlations. These results have not been reported previously. In fact, a previous study reported that practicing Qigong, which is an ancient Chinese psychosomatic exercise that integrates movement, breathing and meditation into a single multifaceted practice, for 1 month enhanced psychological well-being but did not alter TNF-alpha or IFN-gamma levels. ${ }^{23}$ Another study about mindfulness-based stress reduction reported a continued reduction in Th1 (pro-inflammatory) cytokines over one year of pre-post intervention follow-up. ${ }^{24}$ The report that TNF- $\alpha$ showed a significant lower level in the notType D personality+Exercise group ${ }^{25}$ is similar to our result. The increase of IL-10 (anti-inflammatory cytokine) with the decreased tendency of TNF-alpha and IL-6 (pro-inflammatory cytokines) is a new finding beyond the previous results. These new results may have been caused by various factors such as the longer duration of MBT and different MBT methods. The subjects in the MBT group in this study had practiced MBT for a mean of 44 months, and 29 subjects out of total 80 subjects had more than 5 years of MBT experience. Thus, the longer duration of MBT may in part contribute to the increase of IL-10 (anti-inflammatory cytokine) in a specific condition. In addition, this MBT method is both similar to and different from yoga and mindfulness meditation. While yoga focuses on the physical components, mindfulness is related to the mental components of Brain Wave Vibration MBT. Given that this MBT is an eclectic form of Body and Brain Holistic Fitness exercises including physical movements, deep breathing exercises, and meditation practices, this holistic method including both mind and body practices seems to enhance beneficial effects on the immune system. In a previous randomized trial comparing the effects of Brain Wave Vibration MBT with yoga and mindfulness, all interventions improved stress and mindfulness, but Brain Wave Vibration was unique in its benefits to depression and sleep latency. ${ }^{18}$

On the other hand, considering that IL-6 neurons in the hypothalamus are activated, the plasma IL- 6 level increases in response to psychological stress, ${ }^{26}$ while MBT decreases it. ${ }^{11}$ Stress reduction through $\mathrm{MBT}^{2}$ may decrease pro-inflammatory cytokines such as TNF-alpha and IL-6. Improved antioxidant status, both at the enzyme activity and RNA expression levels, has been reported in Sudarshan Kriya (breathing technique) practitioners, suggesting that this practice may have positive effects on immunity, aging, cell death, and stress regulation via transcriptional regulation. ${ }^{27}$ A study by Yang et al. found that magnolol significantly blocks oxidative stress, increases IL-10 and superoxide dismutase activity, and suppresses TNF-alpha and nuclear factor-kB activity. ${ }^{28}$ Therefore, high IL-10 and low TNF-alpha levels in the MBT group would strengthen the immune system, protecting the body from diseases by inhibiting oxidative damage and mental stress. Additionally, body training during MBT may have contributed to the increase in IL-10 and the decrease in TNF-alpha levels. Bastista et al. reported that exercise training increases IL-10 and decreases TNF-alpha levels in the skeletal muscle. ${ }^{29}$ In this cross sectional study, we could not identify the causal effects of MBT; however, we could speculate that the decrease in TNF-alpha and, in part, the increase in IL-10 may be mediated by MBT. Considering that TNF- $\alpha$ blockade induces IL10 expression, ${ }^{21}$ the absence or decrease of TNF-alpha and IL-6 levels (less than 1ng/L) through MBT may contribute to the increase of IL-10. Along with the reduction of pro-inflammatory cytokines (TNF-alpha and IL-6), IFN-gamma seems to assist the increase of IL-10. The synergic and beneficial roles of IFN-gamma for the increase of IL-10 in the MBT group may be associated with IFN-gamma-dependent IL-10 reactivation. ${ }^{30}$ Given that IFN-gamma production was significantly decreased by restraint stress in animal study ${ }^{31}$ and by academic exam stress among healthy and allergic individuals, ${ }^{32}$ IFN-gamma may increase and assist the elevation of IL-10 with stress reduction through MBT. The increase of IL-10 level against TNF-alpha or IL-6 In the low E levels seems to show some counteracting effects of anti-inflammatory cytokine (IL-10) against pro-inflammatory cytokines (TNF-alpha and IL-6). Also, as the increase of $\mathrm{E}$ is associated with stress, ${ }^{22}$ the reduction of E levels may contribute to the increase of IL-10, resulted from the decrease of stress through MBT.

There was a correlation between catecholamines and cytokines in the MBT group but not in the control group, suggesting that MBT may affect the interaction between the immune and nervous systems. Stress reduction through $\mathrm{MBT}^{2}$ may induce interactions between IL-10 and NE/E or DA/E ratio, based on the observation that the low stress group exhibited correlations between the two. On the other hand, the high stress group did not show such correlations between IL10 and catecholamine ratio, implying an important aspect of low stress. When high stress is displayed despite practicing MBT, there is no beneficial interaction between the immune and nervous systems. As the low stress subgroup of the control group did not show any correlation between cytokines and catecholamine ratios, the beneficial interaction between them in the low stress subgroup of the MBT group seemed to be induced by integrative effects with other factors as well 
as stress reduction. One factor among them appeared to be the decreases in pro-inflammatory cytokines, TNF-alpha and IL-6, in the MBT group, because only the subgroup with low TNF-alpha and IL-6 levels (less than $1 \mathrm{ng} / \mathrm{L}$ ) exhibited an interaction between the anti-inflammatory cytokine IL-10 and the NE/E ratio. More importantly, as an interaction between IL-10 and the NE/E or DA/E ratio was seen with less than $1 \mathrm{ng} / \mathrm{L}$ IL-6 levels in the MBT group, the reduction in IL-6 through MBT appears to be a more decisive factor. On the other hand, IL-10 is expected to be an important factor for the beneficial interaction between IL-10 and the NE/E and $\mathrm{DA} / \mathrm{E}$ ratios. The high, but not the low, IL-10 level subgroup of the MBT group displayed this interaction. Thus, the increase in IL-10 through MBT may affect the beneficial interaction between the immune and nervous systems. Stress reduction, decreases in TNF-alpha and IL-6 and an increase in IL-10 through MBT potentially induces synergic effects on the beneficial interactions between the nervous and immune systems. Both the nervous and immune systems are associated with regulating HPA axis-associated stress, ${ }^{4}$ and bidirectional interactions between catecholamines and cytokines affect both systems. ${ }^{33}$ Thus, it is likely that MBT induces a new link between these systems. Correlational analyses can be useful to find the possible interactions of cytokines with catecholamines because there are experimental limitations to find their interactions in vivo human study. Also, as other previous studies used correlation results to explain their interactions, ${ }^{33}$ it can be acceptable to use correlation analyses to infer their interactions between cytokines and catecholamines in this study. As catecholamines may modulate cytokine response in a beneficial way, ${ }^{34}$ the increase in DA in the MBT group ${ }^{2}$ may affect the neuroimmune interactions. Considering that advanced meditators show a significant increase in plasma $\mathrm{NE},{ }^{35}$ the interactions between the NE/E ratio and IL-10 in this study may be associated with advanced meditation. As a slight decrease in the NE/E ratio was observed following mental stress, ${ }^{20}$ the reduction of stress through MBT may affect NE/E ratio and its interaction with IL-10. NE provides long-term protection to dopaminergic neurons by reducing oxidative stress, ${ }^{36}$ and catecholamines drive humoral immunity by stimulating IL-10 macrophage production. ${ }^{37}$ Thus, the increase in DA and the reduction in stress through $\mathrm{MBT}^{2}$ may contribute to the interactions between the DA/E ratio and IL-10. As a result, this may reduce the stress-induced response and improve brain function and the immune system.

However, despite investigating the same MBT, the results of such studies have been contradictory and controversial. Our results are limited by the cross-sectional design of our study. Thus, to confirm our findings, a longitudinal study needs to be conducted using similar measures before and after
MBT. How catecholamines and cytokines may change and affect brain and body functions and mind-body interactions after MBT needs to be explored by an integrated study that includes all biological components involved, ranging from the central nervous system to the peripheral nervous system. Many studies have investigated nonpharmacological methods and various forms of behavioral therapy such as MBT and stress regulation to address pain and psychological distress, ${ }^{38}$ in both distractive and ruminative thoughts/behaviors, ${ }^{39}$ and for treating patients with anxiety disorders, ${ }^{40}$ cancer $^{41,42}$ and rheumatoid arthritis. ${ }^{43}$

In conclusion, MBT was associated with decreases in proinflammatory cytokines and an increase in the anti-inflammatory cytokine IL-10. The MBT group showed positive correlations between cytokines and catecholamine ratios, whereas the control group did not display such correlations. These results support the possibility that MBT may trigger synergistic positive interactions between cytokines and catecholamines, possibly by decreasing pro-inflammatory cytokines and increasing anti-inflammatory cytokines. That is, MBT may regulate the stress system by facilitating more efficient use of energy by improving networks between the nervous and immune systems.

\section{Acknowledgments}

The authors give special thanks to Korean Institute of Brain Science for the assistance in the current study. This research was supported by Grant No. 04-2010-0480 and 04-2012-0790 from the Seoul National University Hospital Research Funds.

\section{REFERENCES}

1. Glannon W. Our brains are not us. Bioethics 2009;23:321-329.

2. Jung YH, Kang DH, Jang JH, Park HY, Byun MS, Kwon SJ, et al. The effects of mind-body training on stress reduction, positive affect, and plasma catecholamines. Neurosci Lett 2010;479:138-142.

3. van Venrooij JA, Fluitman SB, Lijmer JG, Kavelaars A, Heijnen CJ, Westenberg HG, et al. Impaired neuroendocrine and immune response to acute stress in medication-naive patients with a first episode of psychosis. Schizophr Bull 2012;38:272-279.

4. Elenkov IJ, Wilder RL, Chrousos GP, Vizi ES. The sympathetic nerve-an integrative interface between two supersystems: the brain and the immune system. Pharmacol Rev 2000;52:595-638.

5. Dinarello CA. Proinflammatory cytokines. Chest 2000;118:503-508.

6. Stenvinkel P, Ketteler M, Johnson RJ, Lindholm B, Pecoits-Filho R, Riella M, et al. IL-10, IL-6, and TNF-alpha: central factors in the altered cytokine network of uremia--the good, the bad, and the ugly. Kidney Int 2005;67:1216-1233.

7. Dong L, Xia S, Chen H, Chen J, Zhang J. Anti-arthritis activity of cationic materials. J Cell Mol Med 2010;14:2015-2024.

8. von Känel R, Bellingrath S, Kudielka BM. Association between burnout and circulating levels of pro- and anti-inflammatory cytokines in school teachers. J Psychosom Res 2008;65:51-59.

9. Maes M, Scharpé S, Meltzer HY, Bosmans E, Suy E, Calabrese J, et al. Relationships between interleukin- 6 activity, acute phase proteins, and function of the hypothalamic-pituitary-adrenal axis in severe depression. Psychiatry Res 1993;49:11-27.

10. Steptoe A, Willemsen G, Owen N, Flower L, Mohamed-Ali V. Acute 
mental stress elicits delayed increases in circulating inflammatory cytokine levels. Clin Sci (Lond) 2001;101:185-192.

11. Pace TW, Negi LT, Adame DD, Cole SP, Sivilli TI, Brown TD, et al. Effect of compassion meditation on neuroendocrine, innate immune and behavioral responses to psychosocial stress. Psychoneuroendocrinology 2009;34:87-98.

12. Tang YY, Ma Y, Fan Y, Feng H, Wang J, Feng S, et al. Central and autonomic nervous system interaction is altered by short-term meditation. Proc Natl Acad Sci U S A 2009; 106:8865-8870.

13. Infante JR, Torres-Avisbal M, Pinel P, Vallejo JA, Peran F, Gonzalez F, et al. Catecholamine levels in practitioners of the transcendental meditation technique. Physiol Behav 2001;72:141-146.

14. Weller S. Yoga Therapy. London: Thorsons; 1995.

15. Iyenger BKS. Light on Pranayama. New York: Crossroad; 1995.

16. Roth R. Transcendental Meditation. New York: Primus; 1994.

17. Patel C. Yoga-Based Therapy. In: Lehrer PM, Woolfolk RL, Editor. Principles and Practice of Stress Management. 2nd Ed. New York, Guilford, 1999, p.89-130.

18. Bowden D, Gaudry C, An SC, Gruzelier J. A comparative randomised controlled trial of the effects of brain wave vibration training, iyengar yoga, and mindfulness on mood, well-being, and salivary cortisol. Evid Based Complement Alternat Med 2012;2012:234713.

19. Joh TH, Hwang O. Dopamine beta-hydroxylase: biochemistry and molecular biology. Ann N Y Acad Sci 1987;493:342-350.

20. Paran E, Neumann L, Cristal N. Effects of mental and physical stress on plasma catecholamine levels before and after beta-adrenoceptor blocker treatment. Eur J Clin Pharmacol 1992;43:11-15.

21. Evans HG, Roostalu U, Walter GJ, Gullick NJ, Frederiksen KS, Roberts CA, et al. TNF- $\alpha$ blockade induces IL-10 expression in human CD4+ T cells. Nat Commun 2014;5:3199.

22. Maduka IC, Neboh EE, Ufelle SA. The relationship between serum cortisol, adrenaline, blood glucose and lipid profile of undergraduate students under examination stress. Afr Health Sci 2015;15:131-136.

23. Manzaneque JM, Vera FM, Rodriguez FM, Garcia GJ, Leyva L, Blanca MJ. Serum cytokines, mood and sleep after a qigong program: is qigong an effective psychobiological tool? J Health Psychol 2009;14:60-67.

24. Carlson LE, Speca M, Faris P, Patel KD. One year pre-post intervention follow-up of psychological, immune, endocrine and blood pressure outcomes of mindfulness-based stress reduction (MBSR) in breast and prostate cancer outpatients. Brain Behav Immun 2007;21:1038-1049.

25. Hur S, Han GS, Cho BJ. Changes in glucose, TNF- $\alpha$ and IL-6 blood levels in middle-aged women associated with aerobic exercise and meditation training. J Phys Ther Sci 2014;26:1933-1936.

26. Jankord R, Zhang R, Flak JN, Solomon MB, Albertz J, Herman JP. Stress activation of IL-6 neurons in the hypothalamus. Am J Physiol Regul Integr Comp Physiol 2010;299:R343-R351.

27. Sharma H, Datta P, Singh A, Sen S, Bhardwaj NK, Kochupillai V, et al. Gene expression profiling in practitioners of Sudarshan Kriya. J Psychosom Res 2008;64:213-218.

28. Yang TC, Zhang SW, Sun LN, Wang H, Ren AM. Magnolol attenuates sepsis-induced gastrointestinal dysmotility in rats by modulating inflammatory mediators. World J Gastroenterol 2008;14:7353-7360.

29. Batista ML Jr, Rosa JC, Lopes RD, Lira FS, Martins E Jr, Yamashita AS, et al. Exercise training changes IL-10/TNF-alpha ratio in the skeletal muscle of post-MI rats. Cytokine 2010;49:102-108.

30. Shaw MH, Freeman GJ, Scott MF, Fox BA, Bzik DJ, Belkaid Y, et al. Tyk2 negatively regulates adaptive Th1 immunity by mediating IL-10 signaling and promoting IFN-gamma-dependent IL-10 reactivation. J Immunol 2006;176:7263-7271.

31. Himmerich H, Fischer J, Bauer K, Kirkby KC, Sack U, Krügel U. Stressinduced cytokine changes in rats. Eur Cytokine Netw 2013;24:97-103.

32. Trueba AF, Rosenfield D, Oberdörster E, Vogel PD, Ritz T. The effect of academic exam stress on mucosal and cellular airway immune markers among healthy and allergic individuals. Psychophysiology 2013;50: 5-14.

33. Szelényi J, Vizi ES. The catecholamine cytokine balance: interaction between the brain and the immune system. Ann N Y Acad Sci 2007;1113: 311-324.

34. Uusaro A, Russell JA. Could anti-inflammatory actions of catecholamines explain the possible beneficial effects of supranormal oxygen delivery in critically ill surgical patients? Intensive Care Med 2000;26: 299-304.

35. Lang R, Dehof K, Meurer KA, Kaufmann W. Sympathetic activity and transcendental meditation. J Neural Transm 1979;44:117-135.

36. Troadec JD, Marien M, Darios F, Hartmann A, Ruberg M, Colpaert F, et al. Noradrenaline provides long-term protection to dopaminergic neurons by reducing oxidative stress. J Neurochem 2001;79:200-210.

37. Lorton D, Lubahn C, Bellinger DL. Potential use of drugs that target neural-immune pathways in the treatment of rheumatoid arthritis and other autoimmune diseases. Curr Drug Targets Inflamm Allergy 2003; 2:1-30.

38. Carson JW, Keefe FJ, Lynch TR, Carson KM, Goli V, Fras AM, et al. Loving-kindness meditation for chronic low back pain: results from a pilot trial. J Holist Nurs 2005;23:287-304.

39. Jain S, Shapiro SL, Swanick S, Roesch SC, Mills PJ, Bell I, et al. A randomized controlled trial of mindfulness meditation versus relaxation training: effects on distress, positive states of mind, rumination, and distraction. Ann Behav Med 2007;33:11-21.

40. Miller JJ, Fletcher K, Kabat-Zinn J. Three-year follow-up and clinical implications of a mindfulness meditation-based stress reduction intervention in the treatment of anxiety disorders. Gen Hosp Psychiatry 1995; 17:192-200.

41. Carlson LE, Speca M, Patel KD, Goodey E. Mindfulness-based stress reduction in relation to quality of life, mood, symptoms of stress, and immune parameters in breast and prostate cancer outpatients. Psychosom Med 2003;65:571-581.

42. Carlson LE, Speca M, Patel KD, Goodey E. Mindfulness-based stress reduction in relation to quality of life, mood, symptoms of stress and levels of cortisol, dehydroepiandrosterone sulfate (DHEAS) and melatonin in breast and prostate cancer outpatients. Psychoneuroendocrinology 2004;29:448-474.

43. Zautra AJ, Davis MC, Reich JW, Nicassario P, Tennen H, Finan P, et al. Comparison of cognitive behavioral and mindfulness meditation interventions on adaptation to rheumatoid arthritis for patients with and without history of recurrent depression. J Consult Clin Psychol 2008;76: 408-421. 